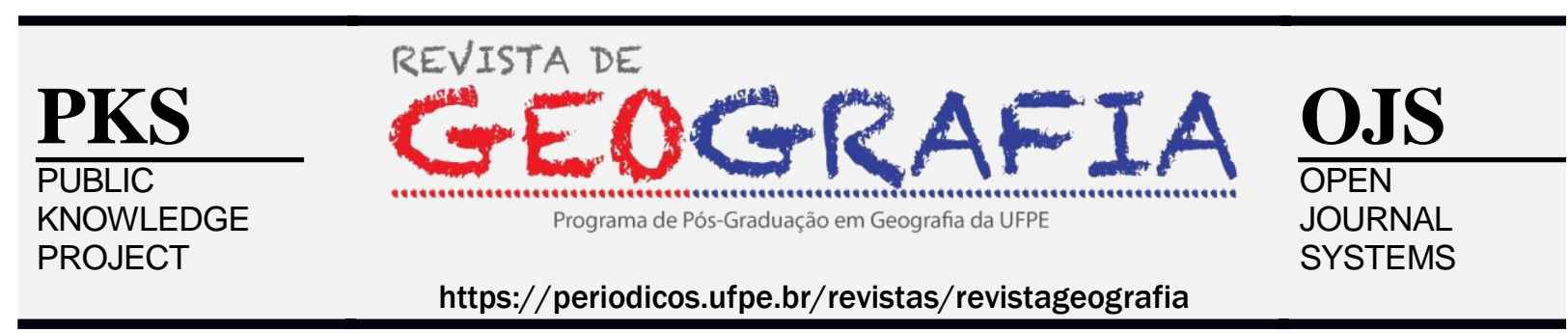

\title{
OS CONCEITOS DA GEOGRAFIA E SUA IMPORTÂNCIA PARA O ENSINO APRENDIZAGEM
}

\author{
Robson Alves do Santos ${ }^{1}$, Dionel Barbosa Ferreira Júnior ${ }^{2}$ \\ ${ }^{1}$ Universidade Federal do Sul e Sudeste do Pará. E-mail: robson.alves@msn.com \\ ${ }^{2}$ Universidade Federal do Sul e Sudeste do Parál.E-mail: dioneljunior41@ gmail.com
}

Artigo recebido em 28/04/2019 e aceito em 25/12/2019

\begin{abstract}
RESUMO
A reflexão apresentada neste artigo trata-se de enfatizar a importância da utilização dos conceitos centrais da Geografia em seu ensino aprendizagem. Propõe-se que as concepções teóricas e metodológicas dos professores de Geografia articule os meios físicos e humanos e suas múltiplas interações na produção do espaço geográfico por meio de seus conceitos centrais como espaço geográfico, território, região, paisagem e lugar. Assim, por meio desses, o aluno deve compreender, entender, e se inserir no mundo, no espaço em que ele vive e pertence e dele participar, construindo seus próprios conhecimentos.
\end{abstract}

Palavras-chave: Conceitos; Espaço geográfico; Ensino aprendizagem.

\section{THE CONCEPTS OF GEOGRAPHY AND ITS IMPORTANCE FOR TEACHING LEARNING}

\begin{abstract}
The reflections in this article is to emphasize the importance of using the central concepts of geography in their teaching and learning. It is proposed that the theoretical and methodological conceptions of geography teachers articulate the physical and human resources and its multiple interactions in the production of geographical space through its central concepts as geographical space, territory, region, landscape and place. Thus, through these, the student must understand, understand, and enter the world in the space in which it lives and it belongs and participate in constructing their own knowledge.
\end{abstract}

Keywords: Concepts; Geographic space; Education learning. 


\section{INTRODUÇ̃̃O}

Na Geografia, a discussão sobre os conceitos geográficos, sempre foi de grande importância, pelo fato destes serem compreendidos como instrumentos fundamentais de compreensão da realidade da sociedade e também por ainda hoje serem considerados as bases para o conhecimento geográfico. Alguns mais velhos e outros mais novos, vão surgindo em razão da necessidade de se compreender as transformações do mundo atual. Neste artigo procura-se realizar um breve entendimento de tais conceitos, bem como a discussão de sua importância para o estudo dos conteúdos geográficos na escola.

A Geografia como ciência e disciplina escolar, tem em seu trajeto histórico, diferentes abordagens que inspiraram práticas pedagógicas diferentes. A princípio se tinha uma Geografia de tendência lablachiana denominada de Geografia Tradicional que no ensino se caracterizava e ainda se caracteriza pelos estudos regionais, descrevendo paisagens naturais de forma dissociada das relações histórico-culturais que produzem o espaço. Na década de 1970, com os estudos marxistas, surgem criticas a Geografia Tradicional no qual a Geografia passase a preocupar-se com a relação sociedade, trabalho e a natureza na produção e apropriação dos lugares e territórios, ou seja, na relação dialética entre a sociedade e o espaço.

Tais mudanças na Geografia, vistas aqui de forma bem resumida sobre seu objeto de estudo, aparecem nas concepções teóricas e metodológicas dos professores desta ciência, e nas práticas pedagógicas e didáticas por eles utilizadas. O que se propõem, é que as concepções teóricas e metodológicas de tais professores de Geografia não sejam somente descritivas, ou que tenha somente uma visão politizada e econômica do mundo, mas que articule os meios físicos e humanos e suas múltiplas interações na produção do espaço geográfico por meios de seus conceitos centrais como espaço, território, região, paisagem e lugar.

Assim, autores como Kaecher (2004), Callai (2005) e Cavalcanti (2006) defendem que o aluno deve compreender, entender, e se inserir no mundo, no espaço em que ele vive e pertence e dele participar, construindo seus próprios conhecimentos por meio dos conceitos básicos e centrais da Geografia. Portanto, o ensino de Geografia por meio de seus conceitos, devem levar em conta o cotidiano no qual o aluno está inserido.

\section{A importância dos conceitos geográficos na Geografia escolar}

Na Geografia, a discussão sobre os conceitos geográficos, sempre foi de grande importância, pelo fato destes serem compreendidos como instrumentos fundamentais de 
compreensão da realidade da sociedade e também por ainda hoje serem considerados as bases para o conhecimento geográfico. Alguns mais velhos e outros mais novos, vão surgindo em razão da necessidade de se compreender as transformações do mundo atual. Neste artigo procura-se realizar um breve entendimento de tais conceitos, bem como a discussão de sua importância para o estudo dos conteúdos geográficos na escola.

A Geografia como ciência e disciplina escolar, tem em seu trajeto histórico, diferentes abordagens que inspiraram práticas pedagógicas diferentes. A princípio se tinha uma Geografia de tendência lablachiana denominada de Geografia Tradicional que no ensino se caracterizava e ainda se caracteriza pelos estudos regionais, descrevendo paisagens naturais de forma dissociada das relações histórico-culturais que produzem o espaço. Na década de 1970, com os estudos marxistas, surgem criticas a Geografia Tradicional no qual a Geografia passase a preocupar-se com a relação sociedade, trabalho e a natureza na produção e apropriação dos lugares e territórios, ou seja, na relação dialética entre a sociedade e o espaço.

Tais mudanças na Geografia, vistas aqui de forma bem resumida sobre seu objeto de estudo, aparecem nas concepções teóricas e metodológicas dos professores desta ciência, e nas práticas pedagógicas e didáticas por eles utilizadas. O que se propõem, é que as concepções teóricas e metodológicas de tais professores de Geografia não sejam somente descritivas, ou que tenha somente uma visão politizada e econômica do mundo, mas que articule os meios físicos e humanos e suas múltiplas interações na produção do espaço geográfico por meios de seus conceitos centrais como espaço, território, região, paisagem e lugar.

Assim, autores como Kaecher (2004), Callai (2005) e Cavalcanti (2006) defendem que o aluno deve compreender, entender, e se inserir no mundo, no espaço em que ele vive e pertence e dele participar, construindo seus próprios conhecimentos por meio dos conceitos básicos e centrais da Geografia. Portanto, o ensino de Geografia por meio de seus conceitos, devem levar em conta o cotidiano no qual o aluno está inserido.

\section{Introdução aos conceitos geográficos}

Os conceitos geográficos possuem muitas definições e interpretações de acordo com a corrente do pensamento geográfico e o momento histórico vivido pela academia. Enfatiza-se que não se pretende realizar uma discussão de grande aprofundamento em torno de tais conceitos da Geografia, mas sim uma breve introdução destes mesmos e sua importância na Geográfica escolar. 
Entre os conceitos da Geografia, o de espaço é o mais amplo do qual derivam e se relacionam os outros conceitos da Geografia como vimos na denominação de constelação de conceitos de Haesbaert (2007). Assim, pode-se dizer que o espaço geográfico é o fruto da ação humana sobre a natureza, modificando-a e transformando-a e, portanto abrangendo o mundo todo.

O conceito de espaço aqui entendido tem a ver com aquele construído historicamente pelo homem e não o que a Geografia Tradicional tinha como foco, onde sociedade humana e natureza eram vistas como unidades de análise separadas. O espaço é historicamente produzido e modificado pelo homem que é agente por excelência do espaço geográfico, pelas relações econômicas e sociais. (VESENTINI, 2004)

Thiesen (2011) afirma que o conceito de espaço é o conceito referencial para o ensino de Geografia e que é importante que no ensino desta, este conceito se converta, por extensão e complexidade, no conceito de lugar para que a compreensão desse mesmo passe a ser referência para a aprendizagem. O mesmo autor pressupõe que:

[...] a Geografia, pelo seu envolvimento interdisciplinar com as demais áreas, deve ser instrumento curricular que possibilite aos sujeitos conhecer, analisar, interpretar e agir na realidade espacial construída e materializada como produto e processo dessas relações sócionaturais. Esse espaço não deve ser visto como recorte da realidade ou apenas como um palco onde as coisas acontecem. Muito além disso, deve ser percebido como lócus de permanente construção, desconstrução e reconstrução, como processos complexos de vida (e de morte), onde se manifestam conflituosamente forças de natureza social, política, ideológica, econômica, cultural, religiosa, natural, etc. (THIESEN, 2011, p.88)

Como disse Lefebvre em 1976 (p. 102)

O espaço não é um objeto científico afastado da ideologia e da política; sempre foi político e estratégico. Se o espaço tem uma aparência de neutralidade e indiferença em relação aos seus conteúdos e, desse modo, parece ser "puramente" formal, a epítome da abstração racional, é precisamente por ter sido ocupado e usado e por já ter sido foco de processos passados cujos vestígios nem sempre são evidentes na paisagem. $\mathrm{O}$ espaço foi formado e moldado a partir de elementos históricos e naturais, mas esse foi um processo político. O espaço é político e ideológico. É um produto literalmente repleto de ideologias. 
Este conceito pode trabalhado em sala de aula, na visão de Lisboa (2007), por meio da identificação das áreas do globo terrestre em que o homem promoveu transformações. Problematizar com os alunos as formas e os meios como a sociedade foi se desenvolvendo demonstrando o aumento da capacidade cada vez maior e de forma mais intensa das modificações no meio natural, enfatizando que as consequências da ação humana são partes essenciais da configuração e produção do espaço geográfico pelo homem acarretando na maioria das vezes em problemas ambientais, decorrentes dessa expansão do espaço geográfico (espaço produzido pelo homem).

O conceito de território é hoje um do mais utilizado pela Geografia, devido ao fato deste estar relacionado de forma mais direta as questões políticas, administrativas, econômicas e de poder. Um dos autores pioneiros na abordagem do conceito de território foi Raffestin (1993), para o autor, ao apoderar-se de um espaço, concreto ou abstratamente, o ator territorializa o espaço. Para este mesmo autor, o território é construído e revela relações marcadas pelo poder, assim, não se pode analisar o território sem levar em consideração as pessoas, ou grupos que exercem o poder e definem o território. Para este mesmo autor o território é:

[...] um espaço onde se projetou um trabalho, seja energia e informação, e que, por consequência, revela relações marcadas pelo poder. (...) o território se apoia no espaço, mas não é o espaço. É uma produção a partir do espaço. Ora, a produção, por causa de todas as relações que envolvem, se inscreve num campo de poder [...] (RAFFESTIN, 1993, p. 144).

Para Vesentini (2004) o território é uma parcela do espaço geográfico apropriada por um sujeito, que tem limites ou fronteiras, ou seja, não existe território sem fronteiras. Podemos também falar em territorialidades, como exemplo, territórios femininos, territórios indígenas, sempre tendo algum tipo de sujeito que exerce poder sobre aquele território e limites, não existe território sem esses dois elementos, sujeito e limites (fronteiras) que e onde termina o território. A respeito da concepção de territorialidade, Andrade a conceitua como identificação e reconhecimento do espaço pela pessoa ou grupo que o habita, isto é, "a formação de um território dá às pessoas que nele habitam a consciência de sua participação, provocando o sentimento da territorialidade" (1993, p. 214).

Haesbaert tem a seguinte definição de territorialidade:

Além de incorporar uma dimensão estritamente política, diz respeito também as relações econômicas e culturais, pois está intimamente ligada ao modo 
como as pessoas utilizam a terra, como elas próprias se organizam no espaço e como elas dão significados ao lugar (HAESBAERT, 2005, p. 6776).

Sobre o conceito de território, para Haesbaert (1997), este tem diferentes abordagens, das quais ele considera três. A primeira, a jurídico-política, no qual o território é um espaço delimitado em que se exerce algum poder de caráter estatal. A segunda, a culturalista, em que se prioriza o subjetivo, o simbólico e a apropriação do território por meio do imaginário de identidade social de determinado espaço. E a última, econômica, que se destaca o que ele chama de desterritorialização, focado em uma perspectiva material, o embate entre classes sociais da relação capital-trabalho.

Assim, partindo de uma ideia geral do conceito de território, pode se dizer que este conceito é a apropriação do espaço identificado pelas relações de poder nele estabelecidas. $\mathrm{Na}$ Geopolítica, este conceito identifica-se como um espaço nacional, uma área controlada por um Estado-nação. O território é fundamental para compreensão dos fenômenos geográfico da organização da sociedade, principalmente no que se refere a formação econômica e social de uma nação partindo do pressuposto de que o trabalho qualifica o território como produto histórico social. (VESENTINI 2004)

Esse conceito, segundo Lisboa (2007), pode ser trabalhado tomando como exemplo a conquista de áreas no período colonial e imperialista o que traria mais significado com a participação do conceito de território, assim como o entendimento do papel do Estado Nacional. Também pode-se, utilizar de exemplo o estudo de outras formas de relações de poder que constituem territórios, em outras escalas de análise, que também se inserem na importância deste conceito como, por exemplo, as reivindicações de sociedades tradicionais ribeirinhas, indígenas e quilombolas.

Já o conceito de paisagem, segundo definição clássica de Santos (1988), é tudo aquilo que nós vemos, o que nossa visão alcança, o domínio do visível, aquilo que a vista alcança e não é formada somente de volumes mas de cores, atores, sons e movimentos. $\mathrm{O}$ mesmo autor em visão mais dialética do conceito de paisagem define essa como uma "realidade provisória, que está sempre por se formar; é um quadro de devir, nunca está pronta e muda a cada momento: em suma é uma realidade efêmera" (SANTOS, 2006, p, 123).

Paisagem é a unidade visível do território e se caracteriza por fatores sejam eles de ordem social, cultural e natural e está relacionada tanto ao passado como ao presente, é o resultado do que ocorreu em determinado espaço em tempos distintos e está cheio de historicidade. (SANTOS, 2006) 
Segundo Lisboa (2007), a paisagem pode ser trabalhado com os alunos destacando as grandes paisagens naturais do globo são um bom conteúdo no qual se pode implementar a discussão da paisagem geográfica; a comparação entre paisagens de diferentes países e até mesmo cidades demonstra como o ambiente e a cultura alteram a forma de intervenção do homem na natureza; e a análise das paisagens urbanas e das áreas industriais constatam o aumento da paisagem humanizada e a capacidade de modificação do espaço e da paisagem pelo ser humano.

Temos o conceito de região, que se caracteriza por um termo amplo, e complexo dentro da Geografia, no qual com a evolução do pensamento geográfico, assim como os outros, o conceito foi se modificando. Para Vesentini (2004) região é sempre a parte de um todo maior, não existe região isolada, sozinha, ou seja, região é a divisão de um espaço em áreas menores.

Para Corrêa, (1987) região é conjunto de lugares onde os contrastes internos entre esses são menores que as existentes entre eles e qualquer elemento de outro conjunto de lugares. Em outras palavras, região é um espaço com características comuns, e quando falamos em regionalização, estamos falando de um processo histórico que ocorreu num dado espaço, produzido pela ação de sujeitos de acordo com seus interesses podendo ser delimitada em diversas escalas de acordo com as necessidades do estudo. No senso comum a expressão região é empregada no cotidiano como uma forma de referência a lugares que se diferenciam uns dos outros.

Para Thiesen (2011), uma das formas de tratar esse conceito com os alunos é pedir que eles dividam o município, ou o bairro em que eles vivem em regiões, questionando-os quais são áreas que eles detectam que possuem características e traços em comum, isso seria uma forma de regionalizar o município ou o bairro, fazendo com que eles tenham uma melhor compreensão do conceito sem esquecer-se da questão da escala.

Para Lisboa (2007), pode se trabalhar esse conceito com os alunos, utilizando-se de exemplos das diferentes propostas de regiões do Brasil e as características comuns dessas mesmas. Através da compreensão desse conceito torna-se fácil identificar como cada tipo de regionalização foi elaborado tendo pressupostos e características comuns que atendam a uma finalidade específica. Os critérios utilizados na regionalização possibilitam ao aluno um olhar através do qual se deseja analisar e compreender a realidade de determinada área.

O processo de regionalização é o que dá origem às regiões. Dessa forma, secciona-se o espaço geográfico em partes que apresentam internamente características semelhantes. Os elementos internos de uma região não são 
idênticos, mas quando comparados aos elementos de outra região se percebe certa homogeneidade interna. Para se empreender um processo de regionalização é preciso estabelecer um conjunto de objetivos e de critérios segundo os quais o espaço será dividido, podendo estes critérios ser de ordem natural, política, econômica, social, etc. Vários tipos de regionalizações para o mesmo espaço podem ser propostos, seguindo objetivos e critérios específicos e promovendo uma sobreposição de regiões. Cada regionalização pode ou não considerar os limites administrativos previamente definidos. (LISBOA, 2011, p.)

O lugar na Geografia, para Vesentini (2004) é o um espaço menor, onde nós vivemos, estudamos, trabalhamos e conhecemos as pessoas, é o espaço com o qual nós, nos identificamos, é o „nosso lugar ${ }^{e e}$. O conceito de lugar trata das referências das pessoas e seus vínculos afetivos, onde se desenvolve sua cultura, costumes e valores é onde os sentimentos de pertencimento e identidade se afloram.

Atualmente o lugar se apresenta como um conceito de maior complexidade, devido aos estudos da Geografia humanística e não mais ligado apenas a noção de escala (cartográfica). O conceito passou a ter uma visão mais ampla e pode ser compreendido como um cotidiano "compartido entre as mais diversas pessoas, firmas, instituições, em cooperação e conflito, sendo a base da vida em comum" (AMORIM, 2006, p. 35). Assim, "na Geografia Humanística, lugar é o espaço que se torna familiar ao indivíduo, é o espaço do vivido, do experienciado." (CAVALCANTI, 1998, p. 89) ou ainda segundo Carlos (2007, p. 19) "O lugar se refere de forma indissociável ao vivido, ao plano do imediato".

O conceito de lugar pode ser trabalhado em sala de aula segundo Lisboa (2007) quando o aluno se depara com o universo da realidade cultural na qual ele esta inserido. Destacar que em muitas situações as características de alguns locais insistem em não desaparecer devido ao processo de globalização da sociedade atual, e o conceito de lugar ajuda a entender esta dinâmica. As questões culturais adquirem importância quando o apego, os sentimentos e a relações dos indivíduos com o seu lugar, parte do espaço geográfico com a qual os antepassados se relacionavam e a comunidade atualmente residente mantêm relação direta. Ao se analisar o processo de globalização pode-se enfatizar que ele muitas vezes ajuda fortificar uma identidade local ao invés de destruí-la. 


\section{Considerações finais}

O objetivo geral deste estudo foi o de apresentar os conceitos da geografia como fundamentais para análise dos fenômenos sob o ponto de vista geográfico nos conteúdos escolares bem como a importância desses conceitos serem utilizados por professores no processo ensino-aprendizagem dos conteúdos de Geografia. Defende-se a idéia de realização de uma abordagem de conteúdo específico para analisar os conceitos centrais da Geografia, a fim de que estes cumpram com seu objetivo de possibilitar uma melhor compreensão das transformações feitas no espaço pelo homem.

Assim, acredita-se na importância da utilização dos conceitos centrais da Geografia em seu ensino-aprendizagem e que os professores devem utilizar destes em suas metodologias, Também se viu uma breve introdução do que seria cada um dos conceitos centrais da Geografia como o de espaço, este visto com um conceito amplo, geral, de espaço geográfico, território, região, paisagem e lugar.

Ao utilizar dos conceitos centrais da Geografia em suas aulas o professor possibilita aos alunos uma visão própria de mundo e das forças que agem e transformam os diferentes territórios. Assim, ele pode agir e interferir como sujeito ativo e atuante na busca de transformações e melhorias na sociedade em que ele vive, seja em uma escala local ou global.

\section{REFERÊNCIAS}

ALVES, A. P. A. F. \& SAHR, C. L. L. Geografia Ensinada - Geografia Vivida? Conceitos e Abordagens para o Ensino Fundamental no Paraná. Revista Discente Expressões Geográficas - UFSC, v. 5, p. 49-60, 2009.

ANDRADE, Manuel Correa de. Territorialidades, Desterritorialidades, Novas Territorialidades: os limites do poder nacional e do poder local. In: SANTOS, Milton (Org.) Território: Globalização e Fragmentação. São Paulo: Hucitec, 1993, pp. 213-220.

AMORIN, M. E. de. O trabalho de campo como recurso de ensino em geografia, em unidades de conservação ambiental - o Parque Estadual de Itapuã, 2006. 170f. Dissertação (Mestrado em Geografia) - UFRGS, Porto Alegre, 2006. 
CALlAI, H. C. Aprendendo a ler o mundo: A geografia nos anos iniciais do ensino Fundamental. São Paulo: Cad. Cedes, Campinas, vol. 25, n. 66, p. 227-247, maio/ago. 2005.

CARLOS, A. F. A. O lugar no-do mundo. São Paulo: LABUR, 2007. p. 16-19.

CAVALCANTI. L. de S. Geografia, escola e construção do conhecimento. São Paulo: Papirus, 1998.

CAVALCANTI, L. de S. Bases teórico-metodológicas da Geografia: uma referência para a formação e a prática de ensino. In: CAVLCANTI, L.S. (Org). Formação de professores: concepções e pratica em geografia Goiânia: Vieira, 2006 p. 27-49.

CAVALCANTI. L. de S. Geografia e práticas de ensino. Goiânia: Alternativa, 2005.

CORRÊA, R. L. Espaço, um conceito chave de Geografia. In: CASTRO, Iná E. GOMES. Paulo C. da C. e CORRÊA, Roberto L. (Org.). Geografia - Conceitos e temas. Rio de Janeiro: Bertrand Brasil, 2003. p. 15-47.

HAESBAERT, R. Des-territorialização e identidade: a rede "gaúcha" no nordeste. Niterói: EdUFF, 1997.

HAESBAERT, R. Da Desterritorialização à Multiterritorialidade. In: ENCONTRO DE GEÓGRAFOS DA AMÉRICA LATINA-EGAL, 10, 2005, São Paulo. Anais... São Paulo: Universidade de São Paulo-USP, 2005. p. 6774-6792. CD.

LEFEBVRE, H. Reflections on the Politics of Space. Trad. M. Endres, Antipode, 8, 1976.

LISBOA, S. V. A importância dos conceitos da Geografia para a aprendizagem de conteúdos geográficos escolares. Revista ponto de vista. v. 4, 2007. Disponível em: http://www.coluni.ufv.br/revista-antiga/docs/volume04/importanciaConceitosGeografia.pdf

Parâmetros Curriculares Nacionais: Introdução aos Parâmetros Curriculares Nacionais/Secretaria de Educação Fundamental - Brasília: MEC/SEF, 1999. 
RAFFESTIN, C. Por uma geografia do poder. Tradução de Maria Cecília França. São Paulo: Ática, 1993.

SANTOS, M. Metamorfoses do espaço habitado. São Paulo: HUCITEC, 1988.

SANTOS, M. P. O espaço humanizado, a paisagem humanizada e algumas reflexões sobre a paisagem em São Paulo no século XVIII e XIX. 2006, 192 f. Tese (Doutorado) - Faculdade de Filosofia, Letras e Ciências Humanas, Departamento de Geografia, Universidade de São Paulo, São Paulo, 2006.

THIESEN. J. S. Geografia escolar: dos conceitos essenciais às formas de abordagem no ensino. Revista Geografia Ensino \& Pesquisa, v. 15, n.1, jan./abr. 2011. p. 83-94.

VESENTINI, J. W. O Ensino da geografia no século XXI. Campinas: Papirus, 2004. 